\title{
Allyl Dibenzoylmethane Derivative: Antimelanoma Activity and Study of Its Molecular Mechanism of Interaction with DNA
}

\author{
Jefferson V. P. B. Baeta, ${ }^{a}$ Ulisses M. S. Andrade, ${ }^{b, c}$ Rayane M. Oliveira, ${ }^{c}$ Leandro Oliveira, ${ }^{c}$ \\ Anésia A. Santos, ${ }^{d}$ Gaspar Diaz-Muñoz, ${ }^{e}$ Márcio S. Rocha ${ }^{c}$ and Marisa A. N. Diaz ${ }^{\odot *, a}$ \\ ${ }^{a}$ Departamento de Bioquímica e Biologia Molecular, Universidade Federal de Viçosa, \\ 36570-900 Viçosa-MG, Brazil \\ ${ }^{b}$ Departamento de Formação Geral, Centro Federal de Educação Tecnológica de Minas Gerais, \\ 35790-000 Curvelo-MG, Brazil

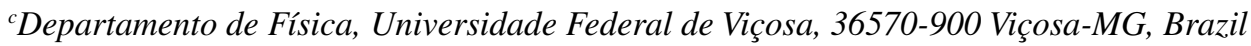 \\ ${ }^{d}$ Departamento de Biologia Geral, Universidade Federal de Viçosa, 36570-900 Viçosa-MG, Brazil \\ ${ }^{e}$ Departamento de Química, Universidade Federal de Minas Gerais, 31270-901 \\ Belo Horizonte-MG, Brazil
}

\begin{abstract}
In this study, we assessed the cytotoxic effect of 1,3-diphenyl-2-allyl-1,3-propanedione (DPAP) on B16F10 and Tm5 melanoma cells and investigated its interaction with DNA (deoxyribonucleic acid) using optical tweezers. The compound showed to be effective against B16F10 cells with selectivity index (SI) of 7.92 and interaction to the outer surface of the double helix, probably at the minor groove of DNA. This likely induced a bending deformation of the polymer chain, decreasing persistence length, and indicated that each DPAP molecule occupies a single base pair upon binding to the double helix.
\end{abstract}

Keywords: DPAP, optical tweezers, DNA, B16F10 cells, Tm5 cells, dacarbazine

\section{Introduction}

Melanocytic neoplasms range from benign lesions, also known as melanocytic nevi, to malignant lesions, termed melanomas. Benign and malignant melanocytic neoplasms develop from melanocytes, neural crest-derived cells that, during development, colonize a variety of tissues throughout the body. ${ }^{1}$ Melanocytes can originate phenotypically different melanomas. Because of this variability, melanoma is one of the deadliest and most metastatic types of cancer. ${ }^{2}$ These malignant tumors have the highest mortality rates of all cutaneous tumors. Whereas the incidence rates of most solid tumors decreased or stabilized in the last decade, that of melanoma increased by $5 \%$ per year. ${ }^{3}$ In Brazil, over 4,000 new cases are diagnosed each year. ${ }^{4}$ In 2020/2022, it is estimated that 4,200 new cases will occur in men and 4,250 in women. Various factors contribute to the development of melanoma, including exposure to UV radiation, genetic factors,

*e-mail: marisanogueira@ufv.br immune conditions, among others. ${ }^{5}$ Drugs that intercalate or interact with DNA (deoxyribonucleic acid) have been widely used as chemotherapeutic agents, among them, dacarbazine is the most used drug to treat melanoma. However, despite its therapeutic success, this drug causes serious side effects, and tumor cells can become resistant to its cytotoxic mechanisms. The mechanism of dacarbazine action involves binding to DNA, preventing DNA strands from separating and disrupting protein and DNA synthesis. This drug is a non-specific agent, as it can act at any stage of the cell cycle. ${ }^{5}$

Dibenzoylmethane (DBM) has been found as constituent of some plants belonging to the Leguminosae family, as minor constituent of licorice. ${ }^{6}$ The first DBM derivative, reported for the first time in Lonchocarpus latifolius (Wild.) $\mathrm{DC}$, is classified as a rare kind of flavonoid, not easily found in nature ${ }^{7}$ (Figure 1).

Nogueira et al. ${ }^{8}$ synthesized a series of DBM derivatives that were tested for cytotoxic activity in human cancer cells, among them, the allyl derivatives stood out. In the present study, motivated by investigations on their use 


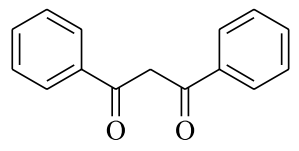

(a)

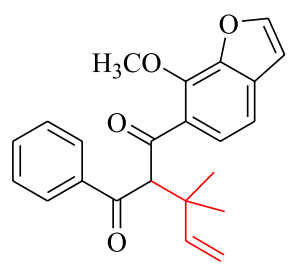

(b)
Figure 1. Chemical structures of (a) dibenzoylmethane (DBM) and (b) dibenzoylmethane derivative isolated from roots of Lonchocarpus latifolius (Wild.) DC.

as therapeutic agents, we evaluated the antimelanoma activity of the DBM derivative 1,3-diphenyl-2-allyl1,3-propanedione (DPAP, Figure 2) against the B16F10 cell line with selectivity index (SI) of 7.92.

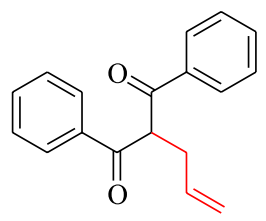

Figure 2. Chemical structure of dibenzoylmethane derivative: 1,3-diphenyl-2-allyl-1,3-propanedione (DPAP).

Its mechanism of action, however, is still unknown, what led us to investigate its efficiency at the molecular level by optical tweezers analysis, a technique used to tether DNA and measure its mechanical properties. This technique allows the elucidation of the binding modes and the physical chemistry of drug-DNA interactions. Such methodology is nowadays recognized as the state-ofthe-art for studying DNA interactions with ligands such as drugs and proteins. ${ }^{9,10}$ It allows one to determine the changes induced by the ligand on the mechanical structure of the double helix upon binding, to unveil the possible binding modes and to determine the complete set of physicochemical (binding) parameters of the interaction. ${ }^{11}$ Thus, these measurements allowed us to perform a very robust characterization of the DPAP mechanism of action on the DNA molecule, which is one of the main targets of current chemotherapeutic compounds. This interest is further enhanced by the incessant search for new, more efficient drugs against melanoma cancer.

\section{Experimental}

\section{General}

${ }^{1} \mathrm{H}$ and ${ }^{13} \mathrm{C}$ nuclear magnetic resonance (NMR) spectra were recorded on a Bruker Avance spectrometer (USA) at 400 and $100 \mathrm{MHz}$, respectively, using $\mathrm{CDCl}_{3}$ as solvents. Chemical shifts $(\delta)$ are given in ppm and coupling constants $(J)$ in Hz. ${ }^{1} \mathrm{H}$ NMR chemical shifts are reported relative to tetramethylsilane (TMS) in $\mathrm{CDCl}_{3}$ as a reference. ${ }^{13} \mathrm{C}$ NMR chemical shifts were recorded using $\mathrm{CDCl}_{3}$ ( $\delta 77.2 \mathrm{ppm}$ ) signal as references. ${ }^{1} \mathrm{H}$ NMR and ${ }^{13} \mathrm{C}$ NMR spectra of compound can be found in the Supplementary Information section. Mass spectrum (MS) was recorded on Shimadzu GCMS-QP2010 Ultra gas chromatograph (Japan) equipped with an Rtx-5MS fused-silica capillary column $(30 \mathrm{~m} \times 0.25 \mathrm{~mm}, 0.25 \mu \mathrm{m}$ film thickness). Helium was used as carrier gas at a constant flow of $1 \mathrm{~mL} \mathrm{~min}^{-1}$. Infrared (IR) spectra were recorded on a Varian 660 FTIR spectrometer equipped (USA) with a diamond attenuated total reflectance (ATR) accessory as a thin film. Melting points were determined on an MQAPF-302 Microchemical apparatus (Brazil) and uncorrected. Purifications were performed by liquid chromatography preparative (HPLC) Prominence LC-20AR Shimadzu (Japan) using Shim-pack PREP-ODS column $20 \times 250 \mathrm{~mm}$, particle size $15 \mu \mathrm{m}$, mobile phase $\mathrm{MeOH} / \mathrm{H}_{2} \mathrm{O}$ 80:20 isocratic and UV-Vis detector. Thin layer chromatography (TLC) visualization on silica gel plates (Darmstadt, Germany) was achieved under ultraviolet light $(254 \mathrm{~nm}$ ) using an darkroom cabinet Trans UV 15LC (São Paulo, Brazil) or by spraying with $5 \%$ ethanolic phosphomolybdic acid and subsequent heating. DBM, allyl bromide, dimethyl sulfoxide (DMSO), 3-(4,5-dimethylthiazol-2-yl)-2,5-diphenyltetrazolium bromide (MTT), deuterated chloroform $\left(\mathrm{CDCl}_{3}\right)$, Roswell Park Memorial Institute (RPMI) medium, Dulbecco's modified Eagle's medium (DMEM), fetal bovine serum, antibiotics (amphotericin B, penicillin, and streptomycin), and $\lambda$-DNA molecules were purchased from SigmaAldrich (St. Louis, MO, USA). B16F10 cells were purchased from ATCC (Manassas, Virginia, USA). Tm5 and melan-A cells were purchased from Leica Biosystems (Wetzlar, Germany), $\lambda$-DNA molecules (48,502 base pairs, $16.5 \mu \mathrm{m}$ contour length) (New England Biolabs). All other chemicals and solvents were of highest purity grade and were purchased from local sources (Sigma-Aldrich, São Paulo, Brazil).

\section{Synthesis of DPAP}

DPAP was prepared according to a reported procedure by Nogueira et al. ${ }^{8}$

\section{Cell lines}

Melan-A cells were established from normal murine melanoblasts; and Tm5 and B16F10 cells from murine melanoma cells. Melan-A cells were cultured in RPMI medium supplemented with $10 \%$ fetal bovine serum, $1 \%$ antibiotics, and $200 \mathrm{nM}$ phorbol 12-myristate 13-acetate. 
Tm5 cells were cultured in RPMI medium supplemented with $10 \%$ fetal bovine serum and $1 \%$ antibiotics. B16F10 cells were cultured in DMEM medium supplemented with $10 \%$ fetal bovine serum and $1 \%$ antibiotics. Cells were maintained in $25 \mathrm{~cm}^{3}$ culture flasks at $37^{\circ} \mathrm{C}, 5 \% \mathrm{CO}_{2}$, and $95 \%$ relative humidity.

\section{Cytotoxic activity measured by the MTT assay}

B16F10 and Tm5 cells were plated at $1 \times 10^{3}$ cells $\mathrm{mL}^{-1}$ and melan-A cells at $1 \times 10^{4}$ cells $\mathrm{mL}^{-1}$. Each well received $100 \mu \mathrm{L}$ of culture medium. Plates were incubated for $24 \mathrm{~h}$ at $37{ }^{\circ} \mathrm{C}, 5 \% \mathrm{CO}_{2}$, and $95 \%$ relative humidity. Different concentrations of dacarbazine (positive control, 1-12 $\mu \mathrm{M})$ and DPAP $(12.5-400 \mu \mathrm{M})$ were added to the wells, and plates were incubated for $60 \mathrm{~h}$ at $37{ }^{\circ} \mathrm{C}, 5 \%$ $\mathrm{CO}_{2}$, and $95 \%$ relative humidity. After this period, the MTT (4,5-dimethylthiazol-2-yl)-2,5-diphenyltetrazolium bromide) assay was performed. Absorbances were read at $570 \mathrm{~nm}$, and the half-maximal inhibitory concentration $\left(\mathrm{IC}_{50}\right)$ was determined for each cell line using non-linear regression of the logarithm of the dose concentration versus the normalized response (percentages of viable cells) with the GraphPad Prism 5.0 $0^{12}$ and Microsoft Office Excel $2013^{13}$ software. Inhibitory concentrations of $90 \%\left(\mathrm{IC}_{90}\right)$ and $10 \%\left(\mathrm{IC}_{10}\right)$ of the cells were also calculated using the same methodology and software.

\section{Selectivity index}

The selectivity index (SI) indicates the potential therapeutic use of compounds in clinical trials. In this study, SI value corresponds to the ratio of $\mathrm{IC}_{50}$ for normal cells (melan-A) to the $\mathrm{IC}_{50}$ for neoplastic cells (B16F10).

\section{Statistical analysis}

$\mathrm{IC}_{50}$ values for tumor cells were analyzed using the GraphPad Prism 5.0 $0^{12}$ software. Statistical differences between experimental groups were assessed by one-way analysis of variance (ANOVA) $(p<0.05)$.

\section{Optical tweezers setup and single-molecule DNA assays}

The optical tweezers system basically consists of a laser beam focused by a high numerical aperture microscope objective. Such instrument is able to use the forces exerted by the focused laser to trap and manipulate micrometersized objects, cells and even molecules, allowing the investigation of the processes related to these systems with a resolution as high as at the single molecule level. ${ }^{14}$
Our tweezers consisted of a 1,064 nm solid-state laser (CNI Laser, China) mounted on a Nikon ECLIPSE Ti2 inverted microscope with a $100 \times$ NA 1.4 objective lens. The instrument was previously calibrated by the drag force method, ${ }^{14}$ and the trap stiffness was found

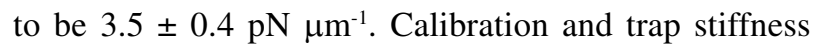
determination are necessary to accurately determine the persistence and contour lengths of bare DNA molecules and DNA-drug complexes. ${ }^{14}$ Samples consisted of $\lambda$-DNA molecules end-labeled with biotin attached by one end to a streptavidin-coated polystyrene bead of $3 \mu \mathrm{m}$ diameter (Bangs Laboratories) and by the other end to a streptavidincoated coverslip. The sample chamber was mounted by gluing an o-ring on the surface of the coverslip. The working solution (phosphate buffered saline, $\mathrm{pH} 7.4$, and $140 \mathrm{mM} \mathrm{NaCl}$ ) containing DNA molecules was deposited directly inside the o-ring. DPAP concentration in the sample was altered during experiments by slowly exchanging the working solution while the DNA remained tethered by the tweezers.

DNA molecules were manipulated and stretched by moving the microscope stage (and consequently the coverslip) at a constant velocity, using a piezoelectric device (PInano ${ }^{\circledR}$, Physik Instrumente). With this procedure, we were able to measure the force-extension curve of the bare DNA molecule and of its complexes formed with DPAP at various different concentrations of the compound. The basic mechanical parameters (persistence and contour lengths) of the DNA molecules and of the DNA-DPAP complexes were determined by fitting the measured force-extension curves to the Marko-Siggia worm-like chain model, ${ }^{15}$ a standard procedure. The experiment was initiated using a sample of bare DNA molecules. A single DNA molecule was stretched and, if the measured contour length agreed with the expected value for $\lambda$-DNA (16-17 $\mu \mathrm{m}$ ), six more stretching measurements were taken, and the mean values of persistence and contour lengths were obtained. Both mechanical parameters were determined by fitting the measured force-extension curves to the Marko-Siggia worm-like chain model. ${ }^{15}$ Then, the surrounding buffer solution was changed, introducing DPAP at the desired concentration. The sample was left for $1 \mathrm{~h}$ to allow DNA-drug complexes to reach chemical equilibrium, and stretching experiments were then repeated. A new set of six measurements was taken. This procedure was repeated sequentially for each DPAP concentration, allowing us to assess the behavior of mechanical parameters (persistence and contour lengths) as a function of drug concentration. More details on these procedures are described elsewhere. ${ }^{14,16}$ 


\section{Results and Discussion}

\section{Chemistry}

DPAP was synthesized by reacting DBM and allyl bromide in acetone in the presence of anhydrous potassium carbonate (Figure 3). DPAP was characterized by ${ }^{1} \mathrm{H}$ and ${ }^{13} \mathrm{C}$ NMR and mass spectra. The spectral data of DPAP agreed with those described in the literature. ${ }^{7}$

\section{Cytotoxicity}

DPAP was more effective against B16F10 cells than against Tm5 and melan-A cells (Figure 4). SI values of DPAP and dacarbazine were 7.92 and 0.96 , respectively, showing that DPAP is highly selective toward B16F10 tumor cells (Table 1).

The results presented in Figure 4 and Table 1 indicate that DPAP is a promising agent for the treatment of melanoma because it presented a higher SI value (7.92) and a lower $\operatorname{IC}_{50}\left(26.17 \mu \mathrm{g} \mathrm{mL}^{-1}\right)$ for cancer cells than those obtained for dacarbazine ( $\mathrm{SI}=0.96$ and $\mathrm{IC}_{50}=258.51 \mu \mathrm{g} \mathrm{mL} \mathrm{mL}^{-1}$, respectively), and $\mathrm{DMB}$ $\left(\mathrm{SI}=2.14\right.$ and $\left.\mathrm{IC}_{50}=11.59\right)$. Although Tm5 cells $\left(\mathrm{IC}_{50}=53.47 \mu \mathrm{g} \mathrm{mL}^{-1}\right)$ were more resistant to DPAP than B16F10 cells $\left(\mathrm{IC}_{50}=26.17 \mu \mathrm{g} \mathrm{mL}^{-1}\right)$, the SI value found for these cell lines was higher than that obtained for the other two drugs. This partial resistance may be related to the fact that the Tm5 cell line was obtained from the transformation of normal melan-A cells into cells<smiles>O=C(CC(=O)c1ccccc1)c1ccccc1</smiles>

Dibenzoylmethane (DBM)
$\mathrm{K}_{2} \mathrm{CO}_{3}$, allyl bromide acetone, r.t. overnight<smiles>C=CCC(C(=O)c1ccccc1)C(=O)c1ccccc1</smiles>

1,3-Diphenyl-2-allyl-1,3-propanedione (DPAP)

Figure 3. Synthesis of 1,3-diphenyl-2-allyl-1,3-propanedione (DPAP).
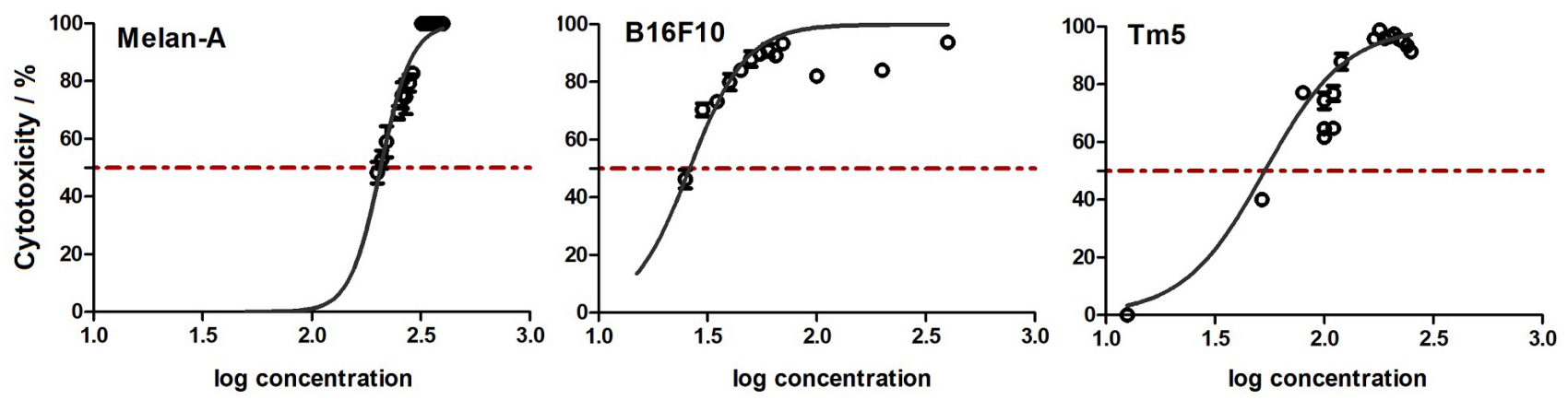

Figure 4. Cytotoxicity of 1,3-diphenyl-2-allyl-1,3-propanedione against melan-A, B16F10 and Tm5 cells. Results are the mean \pm standard deviation of three independent experiments.

Table 1. Half-maximal inhibitory concentrations $\left(\mathrm{IC}_{50}\right)$ and selectivity index (SI) of dacarbazine, dibenzoylmethane (DBM) and 1,3-diphenyl-2-allyl1,3-propanedione (DPAP)

\begin{tabular}{|c|c|c|c|c|c|}
\hline \multirow{2}{*}{ Compound } & \multicolumn{3}{|c|}{$\mathrm{IC}_{50} /\left(\mu \mathrm{g} \mathrm{mL}^{-1}\right)$} & \multicolumn{2}{|c|}{ SI value } \\
\hline & $\mathrm{B} 16 \mathrm{~F} 10$ & Melan-A & Tm5 & Melan-A/B16F10 & Melan-A/Tm5 \\
\hline \multirow[t]{3}{*}{ Dacarbazine $^{a}$} & 258.51 & 246.85 & 1060 & 0.96 & 0.23 \\
\hline & 11.59 & 16.74 & 7.64 & 2.14 & 2.19 \\
\hline & 26.17 & 207.2 & 53.47 & 7.92 & 4.87 \\
\hline DPAP & & & & & \\
\hline
\end{tabular}

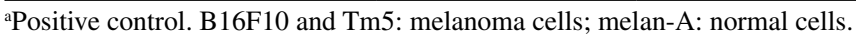


with malignant characteristics (Tm5). ${ }^{17} \mathrm{IC}_{50}$ values for both tumor lines were lower than the $\mathrm{IC}_{10}$ for melan-A (144.75 $\mu \mathrm{g} \mathrm{mL}^{-1}$, Table S1, in the Supplementary Information section). Assessing these results in more detail, we have shown that the DPAP concentration that kills $90 \%$ of the tumor cell population $\left(\mathrm{IC}_{90}\right.$ of $\mathrm{B} 16 \mathrm{~F} 10$ and Tm5) is cytotoxic to less than $10 \%$ of normal cells, that is, the $\mathrm{IC}_{90}$ value for both tumor cell lines was lower than the $\mathrm{IC}_{10}$ for normal melan-A cells. In addition, when comparing the effectiveness of the DBM and DPAP, we have shown that the introduction of an allyl substituent in DBM improved the cytotoxic activity of the compound relative to B16F10 cells about 5.7 times.

\section{Molecular mechanism of action of DPAP and physicochemical characteristics of DNA-DPAP interaction}

Figure 5 shows the measured contour length of DNA-DPAP complexes (L) as a function of drug concentration in the sample $\left(\mathrm{C}_{\mathrm{T}}\right)$. Note that this mechanical parameter remains constant as the drug binds to the DNA molecule, for all tested concentrations. Thus, DPAP does not change the interspace between consecutive base-pairs along the double-helix (ca. $0.34 \mathrm{~nm}$ for B-DNA). Such result discards the possibility of drug intercalation into the double helix as the DNA contour length increases when this type of interaction occurs as a result of drug insertion between adjacent base-pairs. ${ }^{16,18}$

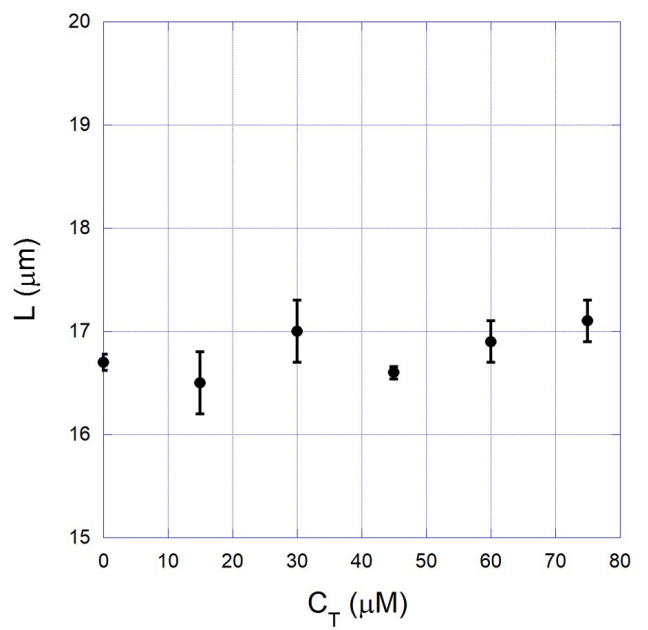

Figure 5. Contour length (L) of DNA complexes formed with 1,3-diphenyl-2-allyl-1,3-propanedione as a function of drug concentration $\left(\mathrm{C}_{\mathrm{T}}\right)$. Note that $\mathrm{L}$ remains constant as drug concentration increases, discarding intercalation as a possible binding mechanism.

Figure 6 shows the corresponding persistence length (A) of the same DNA-DPAP complexes as a function of drug concentration in the sample. We highlight that this mechanical parameter decreases monotonically as the drug binds to the double helix, confirming that there is a significant interaction between DNA and DPAP.

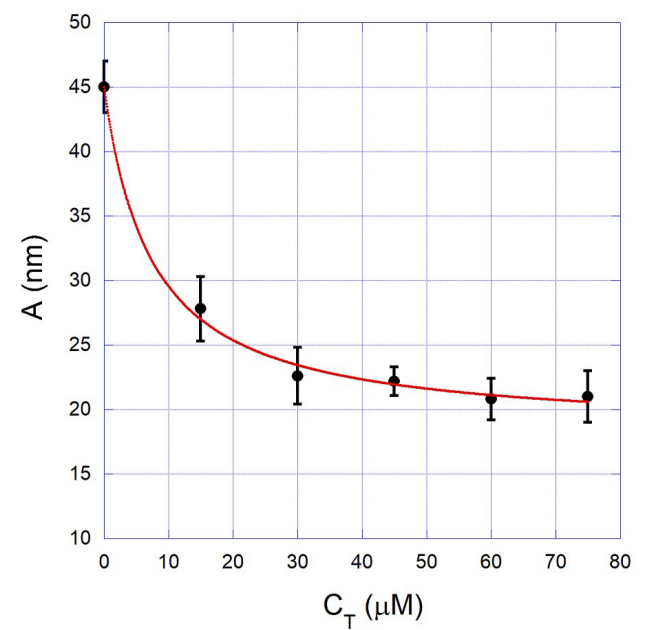

Figure 6. Persistence length (A) of DNA complexes formed with 1,3-diphenyl-2-allyl-1,3-propanedione as a function of drug concentration $\left(\mathrm{C}_{\mathrm{T}}\right)$. Black circles represent experimental data, and the red line is the fit to the quenched-disorder statistical model for drug binding. Model fitting returns the following binding parameters: $\mathrm{K}=(1.1 \pm 0.2) \times 10^{5} \mathrm{M}^{-1}$, $\mathrm{N}=0.9 \pm 0.2$, and $\mathrm{A}_{1}=20 \pm 2 \mathrm{~nm}$.

Experimental data of the persistence length were fitted to a previously developed quenched-disorder statistical model for ligand binding, extensively described in reference. ${ }^{18}$ Such model allows one to determine the physicochemical (binding) parameters of the interaction from the data of Figure 6 (persistence length as a function of the drug concentration, obtained from the optical tweezers experiments). Briefly, the model predicts that a monotonic decrease on DNA persistence length due to drug binding can be modeled by equation 1 :

$\frac{1}{\mathrm{~A}}=\frac{1-\mathrm{r} / \mathrm{r}_{\max }}{\mathrm{A}_{0}}+\frac{\mathrm{r} / \mathrm{r}_{\max }}{\mathrm{A}_{1}}$

where $A_{0}$ is the persistence length of bare DNA, $A_{1}$ is the persistence length of drug-saturated DNA, $r$ is the fraction of occupied DNA base pairs, and $r_{\max }$ is the saturation value of $r$. In order to use equation 1, a binding isotherm must be selected to connect the fraction of occupied DNA base pairs (r) to the ligand concentration in the sample, $\mathrm{C}_{\mathrm{T}}$. Here, we chose the McGhee-von Hippel neighbor exclusion model (NEM) to describe the binding mechanism..$^{18,19}$ The isotherm can be written as equation 2 :

$\frac{\mathrm{r}}{\mathrm{C}_{\mathrm{T}}-\mathrm{rC}_{\mathrm{bp}}}=\mathrm{K}(1-\mathrm{Nr})\left[\frac{1-\mathrm{Nr}}{1-(\mathrm{N}-1) \mathrm{r}}\right]^{\mathrm{N}-1}$

where $\mathrm{C}_{\mathrm{bp}}$ is the DNA base pair concentration in the sample, $\mathrm{K}$ is the equilibrium binding constant, and $\mathrm{N}$ is the exclusion 
parameter (number of base pairs effectively occupied by a single bound drug molecule).

Such binding isotherm was chosen because it can accurately describe a simple monotonic decay of the persistence length such as that presented in Figure. 6, providing that the drug interaction with DNA is noncooperative. ${ }^{18}$ One should note that the model (red solid line in Figure 6) really fits the experimental data very well (black circles in Figure 6). This allowed the determination of the binding parameters with accuracy and showed that the NEM binding isotherm is a good approach for the present interaction. Technical details of the fitting procedure for equations 1 and 2 can be found in reference. ${ }^{18}$ Basically, equation 2 is plugged into equation 1 and least squares fitting is used to fit the composed equation to the experimental data of Figure 6. The following parameters were determined from model fitting: $\mathrm{K}=(1.1 \pm 0.2) \times 10^{5} \mathrm{M}^{-1}, \mathrm{~N}=0.9 \pm 0.2$, and $\mathrm{A}_{1}=20 \pm 2 \mathrm{~nm}$.

The order of magnitude of the equilibrium binding constant is compatible to that of other well-known chemotherapeutic drugs, ${ }^{16,18,20-22}$ indicating that DPAP is a potential candidate for use in chemotherapies. The value obtained for the exclusion parameter, on the other hand, indicates that each DPAP molecule occupies a single base pair upon binding to the double helix. Such result confirms that intercalation cannot be the binding mechanism, as intercalators effectively occupy two to four DNA base pairs because of the pronounced neighbor exclusion effect. ${ }^{22}$ $A_{1}$ reflects the final saturated persistence length induced by the drug upon binding to DNA. On the basis of the results discussed above, we propose the following binding mechanism for the DNA-DPAP interaction: the drug binds to the outer surface of the double helix, probably at the minor groove, as its molecular weight is relatively small (ligands with a molecular weight of less than $1000 \mathrm{~g} \mathrm{~mol}^{-1}$ generally bind to the minor groove instead of the major groove). Such groove binding does not affect the DNA contour length but decreases the effective persistence length of the complex. Drug binding along the minor groove of DNA likely induces bending deformation of the polymer chain, decreasing persistence length. The good fit of the NEM binding isotherm (equation 2) to experimental data indicates that DPAP binding to DNA is non-cooperative (each DPAP molecule binds independently), which was expected because of the simple non-sigmoidal decrease in persistence length. ${ }^{18}$

As mentioned before, optical tweezers technique is nowadays recognized as the state-of-the-art for studying DNA interactions with ligands such as drugs and proteins, ${ }^{9,10}$ allowing a robust characterization of the DNA-drug complexes formed from the physicochemical and structural points of view, as shown by our results. Other typical techniques used in the field, such as nanocalorimetry, gel electrophoresis and the various types of optical spectroscopies, can provide such a rich description of the interaction only when combined together.

In a previous study by our research group on 1,3-diphenyl-2-benzyl-1,3-propanedione (DPBP), shown in Figure 7 alongside DPAP, we observed that DPBP also binds to the minor groove of DNA. ${ }^{11}$

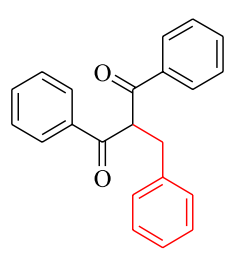

DPBP

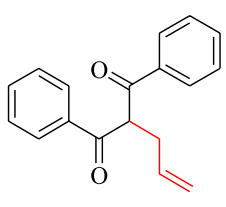

DPAP
Figure 7. Chemical structures of 1,3-diphenyl-2-benzyl-1,3-propanedione (DPBP) and 1,3-diphenyl-2-allyl-1,3-propanedione (DPAP).

However, DPBP likely binds to DNA through partial intercalation, as it has an additional aromatic ring that can be partially inserted into the double helix. DNA contour length increased with DPBP concentration. The interaction of DPAP with DNA is stronger than that of DPBP; the equilibrium association constant of the former is about four times higher than that of the latter. On the other hand, the binding of DPBP is highly cooperative; that is, previously bound DPBP molecules facilitate subsequent binding, contributing to the formation of clusters of bound DPBP molecules. ${ }^{11}$ Such differences suggest that small chemical modifications can induce drastic changes to the compound's molecular mechanism of action. The comprehension of the peculiarities of these mechanisms can allow the development of combined treatments for efficient action against cancer cells.

\section{Conclusions}

In this study, we tested the antineoplastic efficiency of a dibenzoylmethane derivative, DPAP, against B16F10 and Tm5 melanoma cells. Cytotoxicity and selectivity results showed that DPAP can be a promising agent for the treatment of melanoma, presenting a high selectivity for the melanoma cells tested. This selectivity is higher than that presented by the conventional drug, while the inhibitory concentration of malignant cells growth is lower. Singlemolecule DNA assays using optical tweezers allowed us to conclude that the molecular mechanism of action of DPAP within cells involves DNA binding. The results indicated that each DPAP molecule occupies a single base pair upon binding to the double helix, showing that intercalation 
cannot be the binding mechanism, as intercalators generally occupy two to four DNA base pairs. Therefore, DPAP binds to the outer surface of the double helix, probably at the minor groove, as its molecular weight is relatively small.

\section{Supplementary Information}

Supplementary data $\left({ }^{1} \mathrm{H},{ }^{13} \mathrm{C}\right.$ NMR, and mass spectrum) are available free of charge at http://jbcs.sbq.org.br as PDF file.

\section{Acknowledgments}

The work was supported by Fundação de Amparo à Pesquisa do Estado de Minas Gerais (FAPEMIG, grant Nos. APQ-00622-14 and APQ-01927-16), Conselho Nacional de Desenvolvimento Científico e Tecnológico (CNPq, grant Nos. 443566/2014-3 and 403229/2016-2), and the SUSRP (Brazilian Unified Health System Research Program, grant No. APQ-03497-13) for the grants awarded to M. A. N. D. and M. S. R. We also thank the financial support from the Coordenação de Aperfeiçoamento de Pessoal de Nível Superior (CAPES, Finance Code 001).

\section{Author Contributions}

J. V.P. B. B. was responsible for experimental syntheses and compound characterization; U. M. S. A., R. M. O., and L. O. for experimental methodology in optical tweezers; A. A. S. and G. D.-M. for data curation and investigation; M. S. R. analyzed the experimental results and revised the manuscript; M. A. N. D. for supervision, writing-reviewing and editing.

\section{References}

1. Mort, R. L.; Jackson, I. J.; Patton, E. E.; Development 2015, 142, 620 .

2. Shain, A. H.; Bastian, B. C.; Nat. Rev. Cancer 2016, 16, 345.

3. Siegel, R. L.; Miller, K. D.; Jemal, A.; Cancer J. Clin. 2018, 68,7 .

4. Carvalho, C. A.; da Cunha, M. E.; Guigliani, R.; Bakos, L.; Ashton-Prolla, P.; An. Bras. Dermatol. 2004, 79, 53.
5. Alexander, M. M.; Eggermont, A. S.; Robert, C.; Lancet 2014, $383,816$.

6. Fukai, T.; Nishizawa, J.; Nomura, T.; Phytochem. 1994, 35, 515.

7. Magalhães, A. F.; Tozzi, A. M. A.; Magalhães, E. G.; Blanco, I. S.; Nogueira, M. A.; Phytochemistry 1997, 46, 1029.

8. Nogueira, M. A.; Magalhães, E. G.; Magalhães, A. F.; Biloti, D. N.; Laverde, A.; Pessine, F. B.; Marsaioli, A. J.; Il Farmaco 2003, 58, 1163.

9. Alves, P. S.; Mesquita, O. N.; Rocha, M. S.; J. Phys. Chem. B 2020, 124, 1020.

10. Moura, T. A.; Oliveira, L.; Rocha, M. S.; Int. J. Biol. Macromol. 2019, 130, 1018 .

11. Nascimento, F. R.; Moura, T. A.; Baeta, J. V. P. B.; Publio, B. C.; Ferreira, P. M. F.; Santos, A. A.; França, A. A. P.; Rocha, M. S.; Diaz-Muñoz, G.; Diaz, M. A. N.; Biophys. Chem. 2018, $239,1$.

12. GraphPad Prism 5.0; GraphPad Software Inc., San Diego, CA, USA, 2007.

13. Microsoft Office Excel 2013, version 15; Microsoft Corporation, Redmond, Washington, USA, 2013.

14 Jones, H. P.; Maragò, O. M.; Volpe, G.; Optical Tweezers: Principles and Applications, $1^{\text {st }}$ ed.; Cambridge University Press: Cambridge, UK, 2015.

15 Marko, J. F.; Siggia, E. D.; Macromolecules 1995, 28, 8759.

16. Silva, E. F.; Bazoni, R. F.; Ramos, E. B.; Rocha, M. S.; Biopolymers 2016, 107, e22998.

17. Oba-Shinjo, S. M.; Correa, M.; Ricca, T. I.; Molognoni, F.; Pinhal, M. A.; Neves, I. A.; Marie, S. K. N.; Sampaio, L. O.; Nader, H. B.; Chammas, R.; Jasiulonis, M. G.; Neoplasia 2006, $8,231$.

18. Rocha, M. S.; Integr. Biol. 2015, 7, 967.

19. McGhee, J. D.; Von Hippel, P. H.; J. Mol. Biol. 1974, 88, 469.

20. Sischka, A.; Toensing, K.; Eckel, R.; Wilking, S. D.; Sewald, N.; Ros, R.; Anselmetti, D.; Biophys. J. 2005, 88, 404.

21. Oliveira, L.; Rocha, M. S.; Phys. Rev. E: Stat., Nonlinear, Soft Matter Phys. 2017, 96, 032408.

22. Chaurasiya, K. R.; Paramanathan, T.; McCauley, M. J.; Williams, M. C.; Phys. Life Rev. 2010, 7, 299.

Submitted: January 13, 2021

Published online: April 8, 2021 